\title{
Merchandising social transmídia na Rede Globo: uma análise da temática Igbtqia+ em Malhação ${ }^{1}$
}

\section{Transmedia social merchandising: an analysis of Igbtqia+ themes in Young Hearts}

\author{
Yvana Fechine ${ }^{2}$, Cecília A. R. Lima³, Diego Gouveia Moreira4, \\ Gêsa Cavalcanti ${ }^{5}$ e Marcela Chace/ ${ }^{6}$
} (Obitel Brasil), cujos resultados também foram apresentados, em outra perspectiva, em Fechine; Lima; Moreira; Cavalcanti e Chacel (2019).

Professora do Departamento de Comunicação Social e do Programa de Pós-graduação em Comunicação da Universidade Federal de Pernambuco (UFPE). Pesquisadora associada ao Centro de Pesquisas Sociossemióticas e ao Observatório Iberoamericano de Fiç̧ão Televisiva (Obitel). Bolsista de produtividade em Pesquisa do CNPq. Email: yvana.fechine@ufpe.br. Ficção Televisiva (Obitel). Email: cecilia.lima@ufpe.br. Ficção Televisiva (Obitel) Email: diego.moreira@ufpe.br. 


\section{Resumo}

Este artigo tem o objetivo de discutir o conjunto de ações socioeducativas realizado pela Globo em Malhação com foco na questão LGBTQIA+ a partir do casal Michael e Santiago. O trabalho analisa a estratégia transmídia utilizada pela emissora na divulgação de ideias educativas sobre questões de sexualidade e coloca as ações à prova a partir da realização de um grupo focal com pessoas LGBTQIA+, em sua maioria integrantes de movimentos sociais relacionados à temática. A análise permite compreender que é preciso continuar investindo na interdiscursividade e no modelo de produção transmídia para que as ações socioeducativas tenham o efeito pretendido.

Palavras-chave

Ações socioeducativas, telenovela, transmidiação.

\section{Abstract}

This paper aims to discuss aims the set of actions with an educational purpose carried out by Globo in Malhação (Young Hearts) regarding LGBTQIA+ issues. The research analyzes the transmedia strategy used by the broadcaster to disseminate educational ideas on sexuality issues and submits the actions to the test by holding a focus group with LGBTQIA + people, mostly members of social movements related to the theme. Finally, the research shows that it is necessary to continuing investing in transmedia strategies to generate the desired outcome.

\section{Key words}

Socio-educational actions, telenovela, transmedia. 
Para Dominique Wolton (1996), a televisão deveria ter três objetivos: informar, educar e distrair. A teledramaturgia brasileira esforça-se para reunir essa tripla vocação nas chamadas ações socioeducativas ou merchandising social (SCHIAVO, 1995; 2006; BALOGH, 2001). As telenovelas brasileiras levam para o ambiente doméstico enredos ficcionais que buscam retratar questões, públicas ou privadas, próprias da sociedade (LOPES, 2003). Por vezes, assumem um tom pedagógico diante de questões e causas sociais não exatamente para gerar consenso, mas para sensibilizar audiências e propor discussões sobre temas potencialmente controversos. No caso da Rede Globo, maior emissora do país, desenvolveu-se "uma cultura de abordagem das questões sociais em todos os níveis da programação, sempre com uma clara intencionalidade educativa" (SCHIAVO, 2006, p. 2, grifo do autor).

Nos últimos anos, a emissora colocou em foco questões de gênero e sexualidade, que vêm sendo sistematicamente inseridas na agenda de discussão. Cada vez mais produções, em diferentes faixas de horário, ocupam-se da inclusão e representação de personagens que fogem a padrões heteronormativos, quase sempre utilizando de uma abordagem socioeducativa. Nesse mesmo contexto, verifica-se que o cenário da convergência midiática (JENKINS, 2008) interferiu diretamente no modelo de produção dos programas televisivos, que agora transbordam para outros dispositivos e telas. A produção de conteúdos transmídias passou também a colaborar com essas ações socioeducativas, ampliando as oportunidades de contato com o consumidor de televisão e apostando mais diretamente na atividade dos usuários em múltiplos dispositivos midiáticos.

Este artigo tem por objetivo analisar as práticas de merchandising social no contexto da transmidiação, utilizando como estudo de caso a soap opera adolescente Malhação e suas ações voltadas para abordar a temática LGBTQIA+ ${ }^{7}$

Sigla que representa o movimento político e social de inclusão de pessoas de diversas orientações e identidades de gênero. Refere-se, respectivamente, a lésbicas, gays, bissexuais, transexuais ou transgêneros, queer, intersexo, assexual e todas as diversas possibilidades de orientação sexual e/ou identidade de gênero que existam. 
na temporada Vidas brasileiras, exibida pela TV Globo, entre março de 2018 e abril de 2019. Embora se organize a partir de temporadas anuais, Malhação funciona em cada uma delas com estrutura (temática principal, núcleos dramáticos, quantidade e duração de capítulos), enredo e personagens similares aos das telenovelas, o que nos permite analisá-la pelos mesmos parâmetros ao tratarmos do merchandising social. O estudo de caso de Malhação - Vidas brasileiras foi realizado com registros descritivos-interpretativos em diários de observação8, a fim de identificarmos as ações socioeducativas relacionadas ao casal Santiel (Santiago e Michael). Em paralelo, foram acompanhados os perfis da TV Globo no Facebook, Twitter e Instagram, bem como o site Gshow, para observar o lançamento de conteúdos ligados às cenas.

Além disso, a abordagem de casais homoafetivos na teledramaturgia da TV Globo foi avaliada por um grupo focal com integrantes de organizações e movimentos sociais pernambucanos engajados com a defesa dos direitos LGBTQIA+, visando analisar, a partir do lugar de fala privilegiado do grupo, as percepções sobre os esforços da emissora nas ações socioeducativas LGBTQIA+ nas telenovelas. O grupo foi realizado no dia 19 de outubro de 2018.

Por considerar importante compreender opiniões de viés mais crítico a respeito do merchandising social ligado à causa LGBTQIA+, a amostra da pesquisa foi concebida de forma proposital. Privilegiou-se a atuação dos participantes em atividades, pesquisas ou entidades ligadas à reflexão sobre homofobia. A partir de Hair et al. (2014), isso significa que selecionamos pessoas identificadas como especialistas sobre o tema do estudo proposto. Ou seja, os participantes tinham lugar de fala privilegiado em relação à problemática tratada. Ao todo, foram oito participantes, nomeados da seguinte forma: diários de campo, utilizados como ferramenta de sistematização dos dados para sua posterior análise. Os diários são compostos pela transcrição das falas dos personagens em cenas nas quais ficaram claros os esforços de abordar as questões de gênero e sexualidade. 
Quadro 1. Identificação dos participantes do Grupo Focal

\begin{tabular}{|c|l|}
\hline Identificação & \multicolumn{1}{c|}{ Perfil } \\
\hline Participante 1 & $\begin{array}{l}\text { Jovem, por volta de 20 anos, branco, homem cis, homossexual. Contribui para um } \\
\text { programa televisivo que trata sobre visibilidade de LGBTs. }\end{array}$ \\
\hline Participante 2 & $\begin{array}{l}\text { Na faixa dos } 30 \text { anos, mulher cis, branca, homossexual. É militante em várias } \\
\text { organizações e envolvida com produção cultural. }\end{array}$ \\
\hline Participante 3 & $\begin{array}{l}\text { Na faixa dos 30 anos, homem cis, branco, homossexual. É advogado e pesquisador } \\
\text { do tema. }\end{array}$ \\
\hline Participante 4 & $\begin{array}{l}\text { Jovem, na faixa dos 20 anos, mulher de gênero fluido, parda, homossexual, } \\
\text { feminista, organizadora de um evento dirigido a LGBTs. }\end{array}$ \\
\hline Participante 5 & Na faixa dos 50 anos, mulher cis, negra. É professora universitária e pesquisadora. \\
\hline Participante 6 & $\begin{array}{l}\text { Na faixa dos } 30 \text { anos, mulher trans, negra, atua na diretoria LGBTQ de uma } \\
\text { instituição de ensino superior. }\end{array}$ \\
\hline Participante 7 & $\begin{array}{l}\text { Jovem, na faixa dos 20 anos, mulher cis, branca, homossexual. É artista e } \\
\text { engajada em produção cultural. }\end{array}$ \\
\hline Participante 8 & Na faixa dos 40 anos, mulher cis, negra, homossexual, pesquisadora. \\
\hline Fonte: Próprios autores.
\end{tabular}

Este artigo tem como objeto específico analisar de que forma o merchandising social transmídia em Malhação - Vidas brasileiras (2018) foi efetivado. Mas a análise pode subsidiar discussões de caráter mais geral sobre o desenvolvimento de estratégias transmídias nesse tipo de ação na teledramaturgia dentro do cenário da cultura participativa9.

Os comentários do grupo contribuem para uma visão crítica acerca do modo como tais ações são percebidas por pessoas que estão envolvidas com reflexões sobre a visibilidade LGBTQIA+ em suas áreas de atuação. O percurso aqui proposto começa recuperando o conceito de merchandising social, destacando como a inclusão de personagens LGBTQIA+ em telenovelas tem caráter pedagógica, muitas vezes enfrentando reações contrárias, as questões de orientação sexual.

\section{Merchandising social na ficção televisiva brasileira}

Desde a inserção das novelas como parte do cotidiano de um público consideravelmente representativo no Brasil, elas tornaram-se um veículo favorável 
para a inserção de produtos, marcas e também de ideias. Quando possui fins comerciais, as inserções no enredo da telenovela são chamadas, grosso modo, de merchandising editorial (NUNES apud SCHIAVO, 1995). Já o processo de criação de narrativas baseadas em temáticas sociais, com uma finalidade educativa, foi definido por Schiavo (1995) como merchandising social. O conceito está relacionado à criação e expansão de debates sociais, executados de forma estratégica para promover o diálogo entre telespectadores.

De acordo com Lopes (2009), o merchandising social:

[...] tem por objetivos: difundir conhecimentos, promover valores e princípios éticos e universais, por exemplo, a defesa dos direitos humanos, voto consciente etc.; estimular a mudança de atitudes e a adoção de novos comportamentos (inovações sociais) frente a assuntos de interesse público, por exemplo, o aleitamento materno, uso do preservativo, quebra de preconceitos etc.; promover a crítica social e pautar questões de relevância social, incentivando o debate pela sociedade, por exemplo, o desarmamento, educação inclusiva etc. (LOPES, 2009, p. 38).

Os enredos das novelas potencializam os discursos implantados na vida dos personagens por meio do merchandising social, oferecendo ao público a oportunidade de refletir e discutir temas de forma indireta, baseando-se na vivência de personagens fictícios. Por isso, de acordo com Clemente (2009, p. 62), o merchandising social também pode ser tratado como uma ferramenta educativa, pois é inegável o seu poder formador de opinião.

Para Baccega (2003, p.8), "toda a sociedade, com maior, menor ou sem escolaridade, homens e mulheres, crianças, jovens e adultos, residentes nas mais diferentes regiões do país discutem a temática social pautada pela telenovela". No grupo focal realizado pelos autores, o papel social e o potencial educativo das telenovelas foram reconhecidos, mas seus efeitos foram relativizados:

Participante 8: [...] a história das novelas tem trazido a realidade social pra gente poder refletir sobre o que a gente tem, sobre o que acontece no Brasil. Eu acho que tem a coisa positiva, tipo: "ah, tem casais, tem beijo na boca, tem gravidez, tem tantas coisas". Mas aí como a gente reage a isso pode ser positivo ou negativo, a gente vai ver como tá a 
onda de conservadorismo contra a homossexualidade nos últimos tempos. Isso diz também dessa abertura de mostrar realmente o que acontece com as famílias, com os casais, então isso pra mim tem coisas positivas e negativas. Infelizmente, não era pra ser, era pra ser só educativa, pra gente respeitar as pessoas. Mas acho que nem sempre traz essa questão de forma bacana. Isso tem potencializado muito as ações fascistas.

A proposta de estimular debates sobre problemas sociais de interesse público encontra nas estratégias transmídias adotadas pelas telenovelas um aliado, não apenas por propiciar o agendamento de tais temáticas em diferentes meios, mas também por permitir o envolvimento dos telespectadores em novas esferas de discussão. Convidando os espectadores a intervir de modo mais ou menos direto na circulação dos conteúdos, a transmidiação pode ser definida como

[...] um modelo de produção orientado pela distribuição em distintas mídias e plataformas tecnológicas de conteúdos associados entre si e cuja articulação está ancorada em estratégias e práticas interacionais propiciadas pela cultura participativa estimulada pela digitalização e convergência dos meios (FECHINE et. al., 2013, p. 26).

Inseridas dentro desse modelo, as ações de merchandising social também passam por reconfigurações. Embora haja registro de ações socioeducativas em novelas da Globo já nos anos 70, Mulheres apaixonadas (2003) foi uma das primeiras novelas a explorar a articulação entre mídias, apresentando um website próprio com informações associadas ao enredo, como violência contra a mulher, alcoolismo e ciúme.

As ações socioeducativas relacionadas às questões de gênero e sexualidade, nosso foco neste artigo, costumam ser desenvolvidas predominantemente nas chamadas novelas das 21 e 23 horas, destinadas ao público mais adulto. Isso faz de Malhação - Vidas brasileiras um caso ainda mais significativo. A trajetória que leva até a representação de personagens homossexuais e casais homoafetivos na faixa das 17 horas, destinada ao público jovem, foi longa e atravessada por polêmicas e tentativas de silenciamento.

Um dos primeiros personagens homossexuais foi o costureiro Rodolfo Augusto de Assim na terra como no céu, exibida entre 1970 e 1971. Rodolfo 
atendia a um padrão de representação social em que gays costumavam ser "apresentados como mordomos, cabeleireiros, bailarinos e assassinos passionais" (CABRAL, 2007 p. 18). Nos anos 80, as tentativas de representação de personagens homossexuais sofreram censura pela Ditadura Militar. Na década de 90, embora não houvesse uma interdição direta, ainda havia rejeição a esse tipo de representação, como evidenciado pela novela Torre de Babel (1988-1999) com a morte trágica de um casal de mulheres inserido na trama.

A partir dos anos 2000, essas representações e temáticas se tornaram mais frequentes. Mas somente em 2014 casais do mesmo sexo puderam se beijar no horário nobre da TV Globo, com Amor à vida (2013-2014) e Em família (2014). Na mesma medida em que cresce a presença de personagens LGBTQIA+ nas novelas, aumentam as ações socioeducativas, como ocorreu em Liberdade, liberdade (2016) e Segundo sol (2018), que pautaram homofobia e relações homoafetivas, ou em $A$ força do querer (2017), que tratou da transexualidade.

A diretora de responsabilidade social da Globo, Beatriz Azeredo (2019), reconhece a importância que as questões de gênero e sexualidade têm ocupado nas telenovelas da Globo, mas ressalta que não há qualquer direcionamento da empresa aos seus autores em relação à abordagem de tais temáticas. Segundo Azeredo (2019), autores e roteiristas da Globo têm liberdade para eleger os temas a serem abordados nas tramas que desenvolvem. O surgimento de personagens não-heterossexuais e de casais homoafetivos nas novelas é uma demonstração de que "como empresa, sempre estamos olhando para a sociedade e refletindo os temas que estão sendo debatidos". No grupo focal realizado pelos autores deste artigo, foi reconhecida a colaboração dessas ações para tornar os LGBTQIA+ mais presentes no cotidiano dos segmentos sociais mais conservadores:

Participante 1: Minha avó não conhece gay, não conhece lésbica, mas aí ela vai assistindo novela, vai assistindo, [...] aí ela começa a se permitir a pronunciar a palavra homossexual. Não que ela entenda sobre isso, não que ela tenha sido devidamente apresentada a esse universo [...] não é perfeito, mas acho que é um crédito que cabe às novelas. 
Na mesma linha, participantes do grupo destacaram a necessidade de naturalizar temas ainda compreendidos pela maioria da população como estranhos ou distantes.

Participante 4: Eu acho que tanto na questão LGBT, como de outras minorias, e até na rotina das pessoas mesmo, a gente aprende a conviver com o diferente [...] por convivência. Eu acho que é muito mais efetivo quando algo faz parte do seu cotidiano, do que quando é algo apresentado como externo, diferente.

A representação de personagens LGBTQIA+ tem sido marcada pelo que Colling (2007) chama de "narrativa de revelação", uma abordagem em que se enfatiza a descoberta da orientação sexual, o processo de autoaceitação dos personagens e de convívio social. Em outras palavras, quando há um personagem homossexual na novela, não raro, seu papel na trama limita-se ao de ser homossexual e ilustrar uma trajetória de preconceito. No grupo focal, esse tipo de representação unidimensional - assim como o eventual vitimismo dos personagens - foi criticado:

Participante 4: Uma coisa que observo muito, não só nas novelas, mas nas representações LGBT em geral, é que aquele personagem existe e o papel dele naquela trama é ser gay, é ser lésbica. Todo o roteiro é baseado nesse fato, não se complexifica a vida daquela pessoa. Por exemplo, não mostra a mulher lésbica que o drama da vida dela é conseguir emprego x. Não, o drama vai ser sobre ela ser lésbica e o quanto é sofrido e complicado. E isso já faz parte da vida das pessoas. Apresentar essas pessoas como "vida comum" seria mais efetivo. Algo que diz "ah, essa pessoa tá vivendo a dela como eu tô vivendo a minha vida, tá lutando pra pagar os boletos dela que nem eu".

Participante 6: [...] seria mais producente se a gente aparecesse como pessoas que tivessem um cotidiano e que o enredo principal ou o drama [...] não fosse da identidade da orientação sexual, mas assim que ela pudesse aparecer casada com outra mulher ou enfim uma pessoa trans com uma família natural, como se constitui, como a gente tem, mas que o foco não fosse a questão da identidade ou da orientação.

Participantes do grupo focal sinalizaram a importância da participação de pessoas LGBTQIA+ na criação desses produtos, destacando que a comunidade 
deve ser ouvida em suas múltiplas facetas e perspectivas. Neste último ponto, salientamos que um aspecto que foi bastante criticado foi a pequena variedade de representações no que diz respeito às possibilidades de recortes de gênero, classe e raça. A predominância de casais brancos, formados principalmente por homens em situação de privilégio econômico, que atendem a determinados padrões de gênero, foi associada a uma lógica de mercado.

Participante 1: [...] de cabeça, eu consegui pensar em muito mais homens gays do que mulheres lésbicas como personagens em novelas, porque tem uma proximidade com o eixo de mercado, com o poder aquisitivo maior e também tem uma estética de familiaridade mais próxima com a das pessoas que costumam assistir novela.

Participante 4: [...] essas pessoas não estão sendo representadas por uma questão de decência, mas de mercado. E aí, quem é que tem dinheiro? São os LGBTs branquinhos, os gays ricos, que vão casar na igreja, que vão adotar uma criança maravilhosa, sabe?

Os participantes do grupo destacaram ainda a importância de as ações socioeducativas estabelecerem uma relação interdiscursiva com outros produtos, inclusive não ficcionais, da grade de programação, de tal modo que a legitimação de direitos integre todo o discurso da empresa:

Participante 5: [...] precisa de um investimento da própria emissora para que não fique apenas no caso que é retratado na própria novela. [...] o debate poderia acontecer em outros programas, nas ações transmídias etc. O problema é que eu penso que isso não é muito utilizado, utiliza mais a polêmica do que o conteúdo em si. Apresentar questões lésbicas, gays, questões da sexualidade, a maior parte das novelas apresenta, agora o que é que se faz com isso?

Participante 4: De nada adianta o esforço de uma telenovela em conscientizar as pessoas contra a LGBTfobia se os demais programas da grade seguem reforçando estereótipos ou dando espaço para figuras preconceituosas.

Embora esse esforço interdiscursivo não tenha sido reconhecido entre os participantes do grupo focal, Azeredo (2019) assegura que o setor de 
responsabilidade social trabalha com o que denomina "metodologia $360^{\circ}$ ", buscando ofertar os conteúdos socioeducativos também nos programas jornalísticos e de entretenimento, em campanhas específicas e nas redes sociais. É em meio a promessas e a cobranças que o merchandising social LGBTQIA+ em Malhação - Vidas brasileiras torna-se um objeto interessante a ser observado, pois trata-se de um caso em que a Globo explorou de modo mais direto a interdiscursividade em torno da temática e a estratégia $360^{\circ}$, cuja operacionalização depende de um modelo de produção transmídia.

A experiência aponta a potencialidade desse modelo no desenvolvimento de ações socioeducativas capazes de promover um debate mais amplo e transversal. Para estudá-la mais a fundo, optamos pelo uso do estudo de caso (YIN, 2001) como instrumento metodológico.

O estudo de caso tem se tornado a estratégia preferida quando os pesquisadores procuram responder às questões "como" e "por que" certos fenômenos ocorrem, quando há pouca possibilidade de controle sobre os eventos estudados e quando o foco de interesse é sobre fenômenos atuais, que só poderão ser analisados dentro de algum contexto da vida real (GODOY, 1995, p. 25).

De acordo com Yin (2001), o estudo de caso é uma estratégia metodológica importante para as Ciências Humanas, pois permite que o investigador tenha uma visão mais aprofundada do fenômeno estudado, revelando nuances difíceis de serem percebidas numa perspectiva mais geral. O autor define o estudo de caso como uma ferramenta que "investiga um fenômeno contemporâneo dentro de seu contexto da vida real, especialmente quando os limites entre o fenômeno e o contexto não estão claramente definidos" (YIN, 2001, p. 32). Dessa forma, analisar o caso desta temporada específica de Malhação nos fornece instrumentos para compreender de que forma as questões relacionadas à sexualidade têm sido incorporadas na teledramaturgia contemporânea praticada pela emissora de maior alcance no país, como exemplo de uma reconfiguração do merchandising social num modelo de produção transmídia. 


\section{Ações socioeducativas transmídias Igbtqia+ em Malhação - Vidas brasileiras}

Malhação é o mais duradouro produto de ficção seriada voltado para o público jovem da emissora. Está no ar desde abril de 1995, com episódios exibidos de segunda a sexta, ao final da tarde. A soap opera também desponta como um espaço privilegiado de investimento em ações socioeducativas. De 2000 a 2004, $40 \%$ de todas as iniciativas de merchandising social foram de Malhação. Em 2006, Malhação veiculou 314 cenas socioeducativas. Em 2009, 158 de todas as 858 cenas socioeducativas ocorreram em Malhação (COUTINHO; QUARTIERO, 2010).

Nos últimos anos, Malhação desenvolveu um papel mais ativo na representação de questões sociais e identitárias. Essa mudança está relacionada ao modo como as juventudes e os movimentos sociais foram fortalecidos pela emergência de novas formas de militância proporcionadas pelo ambiente on-line (CASTELLS, 2013). Nesse sentido, um dos temas prioritários das ações de Malhação é o "combate ao preconceito e à discriminação" (REDE GLOBO apud COUTINHO; QUARTIERO, 2010, p. 89).

Sócrates, o primeiro personagem declaradamente homossexual de Malhação, apareceu na sexta temporada (2000-2001). Nas temporadas seguintes, alguns outros personagens LGBTQIA+ foram representados em Malhação, mas o aspecto afetivo de suas vidas era uma questão pouco explorada. Só em Malhação - Viva a diferença (2017-2018), um relacionamento homoafetivo teve mais ênfase dentro da narrativa, a partir das personagens Lica e Samantha. O casal protagonizou cenas de beijo até então inéditas na faixa de horário. Vidas brasileiras (2018-2019) incluiu personagens gays, trans e bissexuais. A temporada contou com Gabriela Loran, a primeira atriz transexual a participar do elenco. Vidas brasileiras buscou focar em diferentes aspectos das vidas dessas pessoas, especialmente por meio do casal Michael e Santiago.

Na trama, Michael é um homem cis homossexual que não se deixa restringir por padrões normativos de gênero. Já Santiago é um garoto tímido, habilidoso no futebol e que foge ao estereótipo do homem gay afeminado. Quando chega ao colégio, Santiago ainda está tentando entender por que se sente inadequado no 
mundo. No convívio com Michael, ele percebe que, apesar de serem diferentes, eles possuem algo em comum.

A relação homoafetiva entre Michael e Santiago foi destacada de modo constante durante a temporada, mas analisaremos os momentos de maior ênfase nas ações socioeducativas em torno das questões de gênero e sexualidade e o modo como elas transbordaram para outras mídias. O primeiro caso envolve a situação em que Michael é impedido pelo diretor de entrar na escola por usar um sapato de salto alto, provocando polêmica entre os colegas. No dia seguinte, Michael vai para a escola usando uma saia, gerando debates, especialmente com Santiago. As situações permitiram discutir identidade de gênero e masculinidade, a partir do questionamento sobre o que seria roupa de homem e roupa de mulher (cf. Figura 1).

SANTIAGO E MICHAEL CONVERSAM NA ESCOLA - 14/09/18
Michael: Esse mal-estar todo está acabando comigo. Ok, eu gosto de causar, eu fui assunto
por um momento, mas a verdade é que ninguém lembra mais quando e por que essa polêmica
toda começou?
Santiago: É, pelo menos eu já entendi que alguns direitos devem ser revistos, ainda mais
agora que o mundo tá cada vez mais diferente?
Michael: Dá até vontade de chorar, sabe? Porque finalmente alguém entendeu isso.
Santiago: Mas vem cá, naquele dia que você veio pra cá com roupa de mulher, cê fez isso
pra provocar, não foi?
Michael: É se fosse? Eu não estou dentro do meu direito?
Santiago: É isso que tem que ser discutido
Michael: Olha, quando eu fiz aquilo foi porque eu queria que as pessoas refletissem, sabe?
A roupa é uma coisa criada, então dá pra fazer diferente, ninguém é obrigado a vestir o que
as pessoas mandam.
Santiago: No fundo eu admiro sua coragem (...) Eu me botei no seu lugar e eu entendi, eu
não usaria as coisas que cê usa e não acho que colégio é o lugar pra fazer isso, mas eu entendo
que é um jeito seu de fazer politica.
Michael: Olha, a gente ousa que é pras pessoas se ligarem nas mudanças, sabe?
Santiago: Eu só sei jogar bola.
Michael: Então talvez você devesse escutar as pessoas que precisam correr atrás de direitos.

Figura 1. Cena de Malhação: conversa entre Santiago e Michael. Fonte: Elaboração própria.

O trecho destacado pode ser considerado como socioeducativo não apenas por encenar uma situação de discriminação relacionada às minorias sexuais, mas por confrontar explicitamente o senso comum associado a papéis de gênero, adotando um teor pedagógico. Quando Michael afirma que "A roupa é uma coisa criada, então dá pra fazer diferente, ninguém é obrigado a vestir o que as pessoas 
mandam", sendo posteriormente validado pelo próprio Santiago, nota-se um esforço por parte do roteiro de provocar reflexões nos telespectadores sobre essas questões.

Em outro momento importante da trama, a homofobia foi debatida de modo mais direto. A situação acontece quando Michael é vítima de xingamentos e agredido fisicamente por três outros garotos. Santiago ajuda Michael a se defender dos agressores e o incentiva a prestar queixa. Em capítulos anteriores, o próprio Santiago havia sido vítima de preconceito. Ao rejeitar as investidas de uma colega, é acusado de ser gay e torna-se alvo de boatos sobre sua orientação sexual na escola. Percebendo a angústia de Santiago, Michael passa a escrever para ele anonimamente, tentando ajudá-lo no processo de autoaceitação. Em uma das cenas, Santiago chega a pedir ajuda a uma amiga para deixar de ser gay (cf. Figura 2). O conflito do personagem insere na trama a polêmica "cura gay".

SANTIAGO PEDE AJUDA PRA DEIXAR DE SER GAY - 01/10/18
Santiago: Eu não quero mais ser gay, eu quero mudar.
Talissa: Me dá um abraço. Eu posso te levar na minha mãe, ela te conhece, ela viu nos búzios
o que estava acontecendo com você antes de você mesmo entender, mas ela não vai te ajudar
do jeito que você tá pensando. Ela não vai mudar você, ela pode te ajudar com a forma como
você se vê..
Santiago: Sei lá, não falam tanto de cura gay, será que não rola?
Talissa: Meu bem, imagina se eu dissesse pra você que eu quero uma cura pra deixar de ser
quem eu sou, para parar de amar minha mãe, minha fillha, o Vinicius, minha mãe Oxum, o que
é que você ia me dizer? (...) Essa coisa de cura gay é a maior bobagem que já eu ouvi na
minha vida, ser gay não é doença, não precisa de cura.
Santiago: Sei lă, por que as pessoas não conseguem aceitar isso?
Talissa: Eu não sei. Eu queria poder te responder isso, mas eu não sei, eu não sei porque o
preconceito existe, mas eu sei que a gente tem que lutar contra ele.
Santiago: Parece que as pessoas não tentam mudar nem um pouquinho, (...) é cansativo isso.
Talissa: (...) muda sim, muda um pouquinho, depois mais um pouquinho. Sabe o que uma
amiga minha que estava fora do Brasil me disse? Ela me disse que ela viu bandeira do orgul-
ho gay até dentro das igrejas (...) alguns lugares aceitam mais, outros aceitam menos, o único
lugar que não pode ter rejeição é aqui ó, dentro do nosso coração.

Figura 2. Cena de Malhação: cura gay.

Fonte: Elaboração própria.

Neste exemplo, a trama se aproveita de um debate social bastante ativo no momento da exibição da soap: as terapias de reorientação sexual. Especialmente entre 2017 e 2018, ano de exibição de Vidas brasileiras, a discussão tomou fôlego devido à autorização da prática pela via psicológica - decisão posteriormente 
derrubada pelo Supremo Tribunal Federal (STF). Desse modo, Malhação utilizou seu espaço de amplo alcance entre jovens para posicionar-se com um discurso contrário à noção de que a homossexualidade constituiria uma doença que pode ser curada ou um comportamento que pode ser revertido. A cena também pode ser considerada como socioeducativa por adotar um tom de conscientização, como se identifica por exemplo em trechos como "o único lugar que não pode ter rejeição é aqui ó, dentro do nosso coração".

As cartas anônimas que Michael envia a Santiago constroem não apenas a aproximação entre os dois, mas também servem de pretexto para colocar em pauta outros conflitos identitários dos adolescentes homossexuais. O ponto alto do merchandising social envolvendo os dois personagens é a situação na qual o time do colégio ganha o torneio de futsal e Santiago dedica o prêmio a Michael. Eles comemoram o título com um beijo, o primeiro entre dois homens em toda a história de Malhação. A partir daí, Michael e Santiago não escondem mais o relacionamento: andam de mãos dadas, trocam carinhos, comportam-se como namorados, o que teve uma repercussão positiva entre o público LGBTQIA+ que consome Malhação. Esse resultado, evidenciado pelas redes sociais digitais, não pode ser atribuído apenas às cenas exibidas na TV. A estratégia transmídia adotada pela emissora no merchandising social de gênero e sexualidade de Malhação teve também um papel decisivo, como veremos na seção a seguir.

\section{Ação socioeducativa transmídia em Malhação}

O mapeamento que nos permitiu constatar a articulação entre mídias nessa ação socioeducativa em Malhação foi feito a partir da presença da temática de gênero e sexualidade nas redes sociais digitais e em outros produtos da emissora:

Com o processo de transmidiação da novela, as ações socioeducativas também passaram a contar com manifestações não apenas na TV, mas também nos conteúdos lançados pela emissora em múltiplas plataformas. O boca a boca da era digital, propiciado pelo estímulo à cultura participativa e também pela TV social , é essencial como meio de garantir que o tema abordado na novela seja discutido também nos outros espaços acessados pelo público, como redes sociais on-line e aplicativos (FECHINE et al., 2019, p. 137-138). 
Foram identificados diferentes espaços na grade televisiva e nas plataformas online da emissora, nos quais a temática LGBTQIA+ foi explorada concomitantemente ao desenrolar da trama (cf. Figura 3), ecoando os conflitos e situações vividos pelos personagens. Na televisão, o tema foi discutido em programas de entretenimento, como Vídeo Show, e em outros em que há também apelo jornalístico, como o Encontro com Fátima Bernardes, no qual a apresentadora costuma promover debates sobre temas da atualidade.

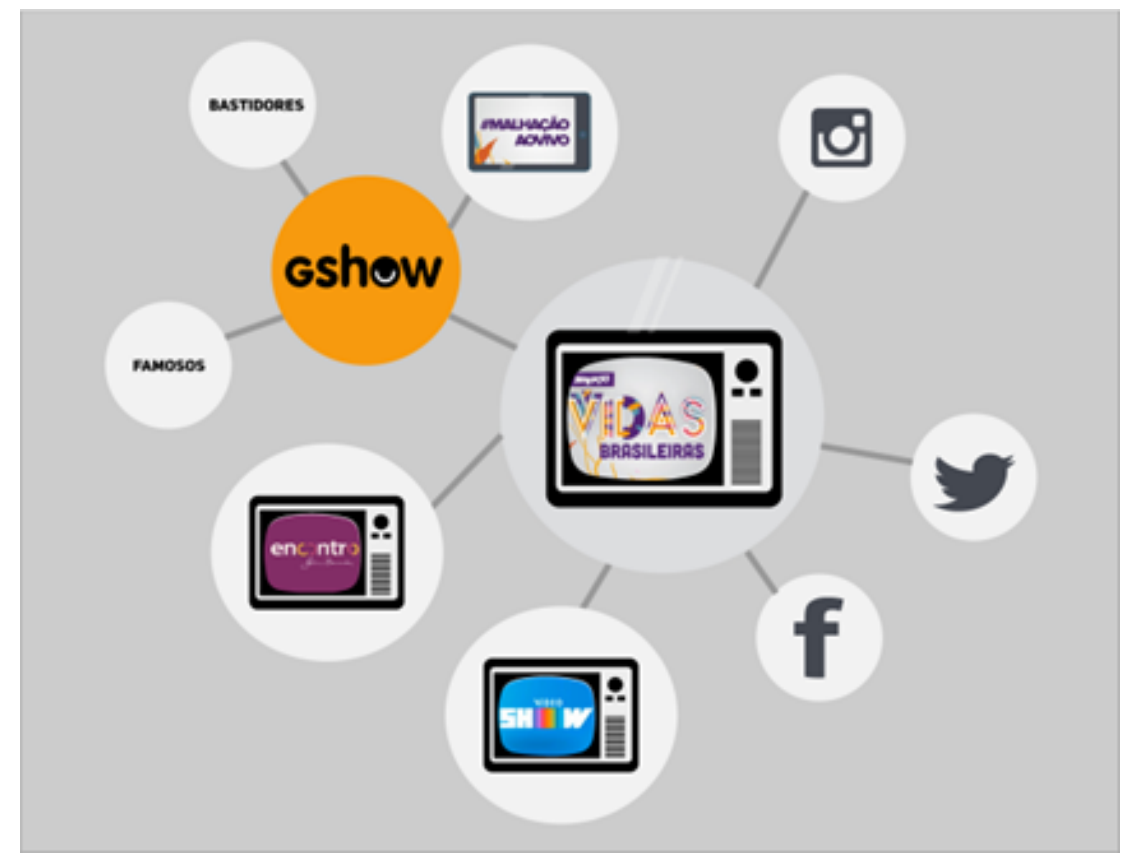

Figura 3. Estratégia transmídia e 360 graus de conteúdos sobre Malhação. Fonte: Elaboração própria.

Nas plataformas on-line, foram verificadas duas principais fontes: o site de entretenimento Gshow e as redes sociais digitais. No Gshow, a construção de um debate relacionado às ações socioeducativas ocorreu, sobretudo, por meio do canal Malhação ao Vivo. O programa quinzenal era usado para apresentar as temáticas discutidas na trama e para ouvir o público com relação ao assunto. Os atores falavam da experiência de viver aquele personagem, bem como da importância do tema. Os fãs enviavam perguntas que eram respondidas durante o programa. Havia também uma curadoria prévia de comentários de fãs que poderiam ser incluídos na 
transmissão. O programa também incluía um fluxo de comentários que incorporava, em tempo real, publicações realizadas no Twitter usando a sua respectiva hashtag ${ }^{10}$.

O programa que foi ao ar no dia 3 de outubro de 2018 recebeu os atores Pedro Vinícius (Michael) e Giovanni Dopico (Santiago). Os atores contaram sobre a construção dos personagens, a importância daquela representação e sobre como foram procurados por diversas pessoas LGBTQIA+ que usaram seus perfis em redes sociais ou a hashtag da novela para falar sobre como se sentiram representados, compartilhando suas dores, histórias de amor etc. A edição contou com depoimentos diversos, incluindo pessoas LGBTQIA+ com influência nas redes sociais digitais.

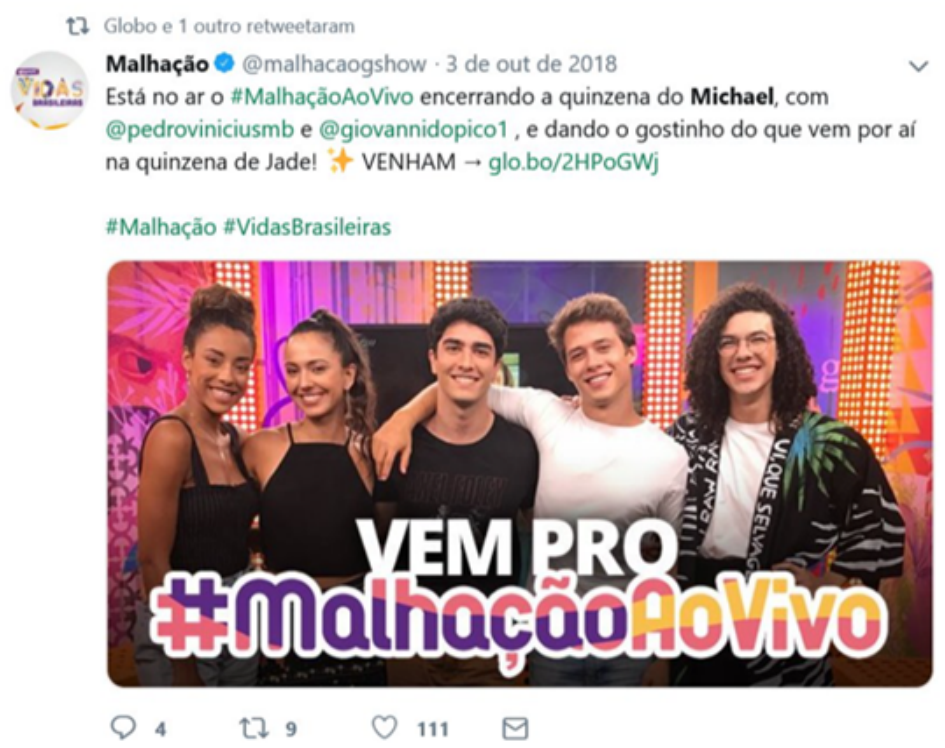

Figura 4. Chamada para o \#MalhaçãoAoVivo.

Fonte: twitter.com/malhacaogshow.

A temática LGBTQIA+ também foi explorada na seção "Bastidores" e "Celebridades" do portal Gshow. Foram disponibilizados matérias e vídeos nos quais os atores falavam da importância dos personagens, da construção de um futuro mais igualitário e do papel da TV nesse processo. A emissora também publicou com frequência assuntos relacionados à relação homoafetiva entre Santiago e Michael 
em suas redes sociais digitais, configurando estratégias transmídias de propagação Segundo Fechine et al. (2013), as estratégias transmídias de propagação referemse à produção. de conteúdos com o objetivo de apenas reverberar e repercutir conteúdos televisivos em outras plataformas, sem que haja uma função narrativa prevista nessas extensões. Já as estratégias de expansão podem ser consideradas como desdobramentos do universo narrativo propriamente dito.

Outras práticas usadas nas redes sociais digitais foram chats com os atores nos quais falavam sobre seus personagens e respondiam a perguntas dos fãs. Assim como outras postagens de estímulo à conversação em torno dos acontecimentos da narrativa, essas ações ocorriam enquanto os capítulos eram exibidos, explorando principalmente o Twitter (live-tweeting).

Em outros programas da TV Globo, o elenco de Malhação foi convocado para colaborar com a ação socioeducativa. O Vídeo show convidou Gabriela Loran, que deu uma entrevista falando sobre como foi viver a primeira personagem transexual da soap opera e o significado disso para quem tem a mesma condição que a sua. Os atores que interpretaram Michael e Santiago participaram do Encontro com Fátima Bernardes, onde conversaram sobre os personagens e ouviram depoimentos de pessoas que haviam passado por situações semelhantes àquelas apresentadas na trama.

\section{Gshow curtiu}

Malhaçăo @malhacaogshow - 10 de out de 2018

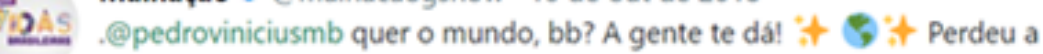
participação no nosso 'Michael' no @EncontroFatima?! Então corre pro link goo.gl/Gyblho

• "Encontro $\boldsymbol{V}$ "Malhação $\cdot$

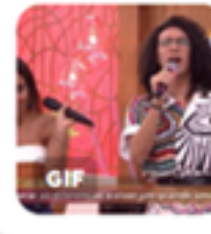

Encontro com Fátima $\bigcirc$ @encontroFatima

[legende este gif] \#AnittaNoEncontro \#Encontro

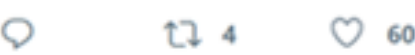

Figura 5. Chamada do perfil de Malhação para o programa Encontro Fonte: twitter.com/malhacaogshow. 
Vale destacar a integração estratégica das mídias, já que o perfil de Malhação no Twitter também divulgava a participação dos atores nos programas da grade televisiva, retroalimentando o circuito de interesse sobre o tema (cf. Figura 5). A efervescência nas redes sociais e efeito conversacional em torno das discussões levantadas por Malhação demonstraram uma estratégia transmídia a serviço da ação socioeducativa. A Figura 6 recupera alguns comentários publicados na página de Malhação, no Facebook, por ocasião da cena de beijo entre os rapazes.
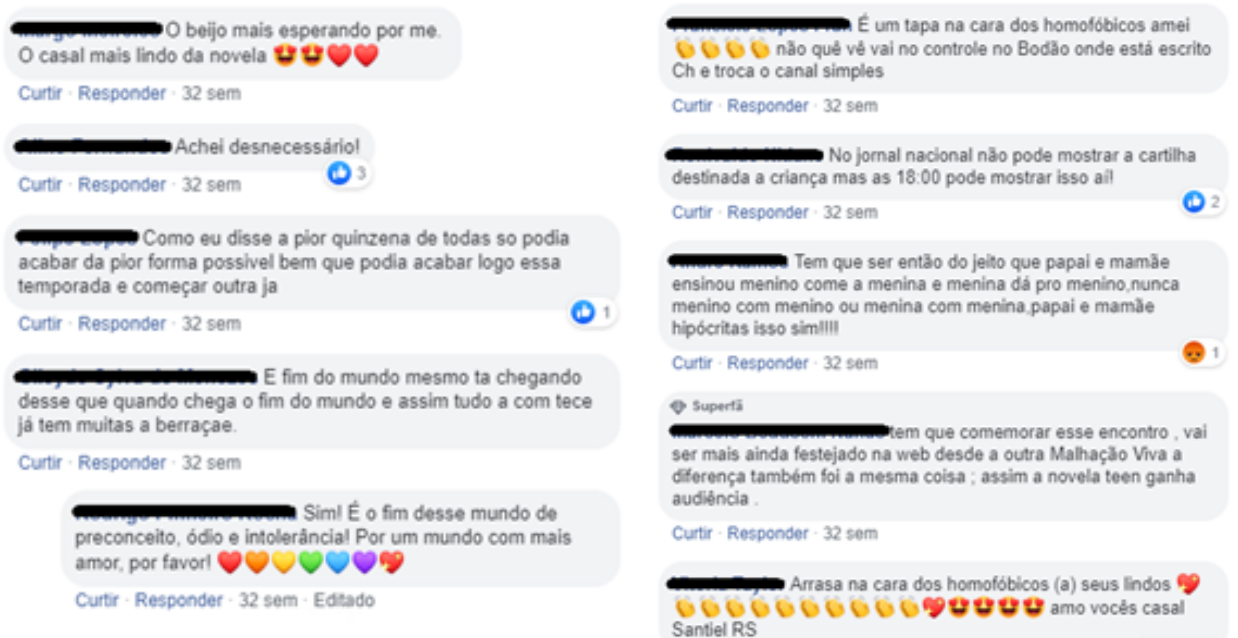

Figura 6. Comentários sobre o beijo de Santiago e Michael no Facebook.

Fonte: facebook.com/malhacao.

Nota-se acima o papel dos ambientes digitais oficiais da Rede Globo como espaços de conversação onde a ação socioeducativa reverbera. O conteúdo é comentado por pessoas que concordam e discordam das ações, de acordo com seus sistemas de valores.

\section{Conclusões}

A partir do caso de Vidas brasileiras, constata-se que a inclusão de personagens LGBTQIA+ em telenovelas pode constituir-se como ação socioeducativa, apesar de suas limitações em representar personagens de diferentes perspectivas de raça, classe e padrões estéticos. No contexto da cultura da convergência, as ações 
adotadas extrapolaram a própria televisão, propondo conteúdos e conversações em diversos ambientes, explorando a possibilidade de participação dos espectadores pelas plataformas digitais interativas. Na opinião da maioria dos participantes do grupo focal, esse investimento interdiscursivo e transmídia é necessário para que a função pedagógica da telenovela se cumpra.

Na experiência de Malhação, como foi visto, a temática ocupou outros espaços na grade de programação, mas é importante destacar a necessidade de coerência no discurso em defesa de direitos entre os programas e nos mais diversos gêneros televisuais, incluindo o telejornalismo, especialmente se o propósito socioeducativo é uma premissa assumida pela emissora.

O ambiente de convergência também dá visibilidade à opinião dos espectadores - que podem discordar das ações voltadas para questões de gênero e sexualidade -, permitindo o envolvimento e o embate de opiniões, necessários para o agendamento social dos temas propostos. Vidas brasileiras recebeu críticas de setores conservadores pelo posicionamento político assumido. No entanto, o mesmo ambiente serviu para que o público LGBTQIA+ se posicionasse em defesa dessas ações, demonstrando o caráter controverso da temática e o papel da ação em facilitar conversações entre grupos de ideologias distintas.

O esforço das ações socioeducativas na telenovela e nas suas estratégias transmídias contribuiu para a discussão do tema, embora não haja meios de garantir que a intenção pedagógica produziu efeitos reais. $O$ conjunto de iniciativas descrito nos permite, porém, constatar que, no caso de Malhação - Vidas brasileiras, houve esforço voltado para a circulação dos temas para além do que estava sendo apresentado na narrativa principal do produto, inserindo a ação socioeducativa proposta no modelo de produção transmídia. Além do estímulo conversacional provocado pelas ações, sejam elas síncronas ou não, merece destaque a recirculação dos temas dentro da própria grade televisiva. É importante realçar, por fim, o estímulo à participação dos espectadores, por meio da articulação com a redes sociais, nas discussões desencadeadas pela trama, o que confirma a potencialidade do modelo de produção transmídia para o êxito das ações socioeducativas. 
Para este tipo de ação, que tem um caráter pretensamente pedagógico, também registramos a importância de criar maneiras de avaliação que passem pela escuta dos grupos envolvidos com a causa a que se busca representar. No caso do grupo focal realizado, um grande conjunto de saberes e vivências pôde ser compartilhado a partir da telenovela, o que atesta, mais uma vez, seu próprio potencial em suscitar tais conversações, mas que também sugere formas de produção que contemplem diversos modos de participação.

\section{Referências}

AZEREDO, B. Entrevista concedida por e-mail ao grupo Obitel-UFPE. Recife, 26 fev. 2019.

BACCEGA, M. A. Narrativa ficcional de televisão: encontro com temas sociais. Comunicação \& Educação, n. 26, 2003. Disponível em: http://www.revistas.usp.br/ comueduc/article/view/37468. Acesso em: 21 mar. 2019.

BALOGH, A. M. O discurso ficcional na TV. Sedução e sonho em doses homeopáticas. São Paulo: Edusp, 2001.

CABRAL, F. Paraíso tropical e a representação homossexual nas novelas da Rede Globo. Monografia do Curso de Comunicação Social. PUC-Rio: Rio de Janeiro, 2007.

CASTELLS, M. Redes de indignação e esperança: movimentos sociais na era da internet. Rio de Janeiro: Zahar, 2013.

COLLING, L. Personagens homossexuais nas telenovelas da Rede Globo: criminosos, afetados e heterossexualizados. Revista Gênero, v. 8, n. 1, 2007. 
CLEMENTE, A. S. Merchandising social: a caixa de Pandora da novela brasileira. Comunicação e Inovação, v. 11, n. 20, jan.-jun. 2010. Disponível em: http://seer.uscs.edu.br/index.php/revista_comunicacao_inovacao/article/ download/950/773. Acesso em: 12 mar. 2019.

COUTINHO, L. M.; QUARTIERO, E. M. O merchandising social em Malhação: estratégias socioeducativas para adolescentes. Revista Educação em Questão, v. 39, n. 25, set.-dez. 2010. Disponível em: https://periodicos.ufrn.br/educacaoemquestao/ article/view/4015. Acesso em: 02 abr. 2019.

CZIZEWSKI, C. C. Telenovela, agendamento e temáticas sociais: uma relação sistêmica e progressiva. Revista Temática, Ano VI, n. 10, 2010.

FECHINE, Y.; GOUVEIA, D. ; LIMA, C.; COSTA, M.; ESTEVÃO, F. Como pensar os conteúdos transmídias na teledramaturgia brasileira? Uma proposta de abordagem a partir das telenovelas da Globo. In: LOPES, M. I. V. (org.). Estratégias de transmidiação na ficção televisiva brasileira. Porto Alegre: Sulina, 2013.

FECHINE, Y.; LIMA, C.; MOREIRA, D.; CAVALCANTI, G.; CHACEL, M. Ações socioeducativas nos mundos da telenovela transmídia: um estudo a partir da abordagem de questões LGBTQIA+. In: LOPES, M. I. V. (org.). A construção de mundos na ficção televisiva brasileira. Porto Alegre: Sulina, 2019.

GODOY, A. S. Pesquisa qualitativa: tipos fundamentais. Revista de Administração de Empresas, v. 35, n. 3, maio-jun. 1995.

HAIR, J. F.; CELSI, M. W. ; ORTINAU, D. J. ; BUSH, R. P. Fundamentos de pesquisa de marketing. Porto Alegre: AMGH, 2014.

JENKINS, H. Cultura da convergência. São Paulo: Aleph, 2008. 
LOPES, M. I. V. Telenovela brasileira: uma narrativa sobre a nação. Comunicação \& Educação, São Paulo, n. 26, p. 17-34, abr. 2003. ISSN 2316-9125. Disponível em: http://www.revistas.usp.br/comueduc/article/view/37469/40183. Acesso em: 13 fev. 2017.

. A telenovela como recurso comunicativo. Revista Matrizes, v. 3, n. 1, dez.-ago. 2009. Disponível em: https://bdpi.usp.br/bitstream/handle/BDPI/32406/ art_LOPES_Telenovela_2009.pdf?sequence=. Acesso em: 20 mar. 2019.

SCHIAVO, M. R. Dez anos de merchandising social. In: Anais. XXIX Congresso Brasileiro de Ciências da Comunicação, 2006. Disponível em: http://www.portcom. intercom.org.br/pdfs/120978737171710494144163695234717744651.pdf. Acesso em: 12 mar. 2019.

. Merchandising social: uma estratégia de sócio-educação para as grandes audiências. Universidade Gama Filho, Rio de Janeiro, 1995

WOLTON, D. Elogio do grande público: uma teoria crítica da televisão. São Paulo: Ática, 1996.

YIN, R. Estudo de caso: planejamento e métodos. 2a. ed. Porto Alegre: Bookman, 2001.

Submetido em: 8 set. 20 | aprovado em: 14 out. 20 